\title{
Urban Train Soil-Structure Interaction Modeling and
} Analysis

\author{
Danial Mohammadzadeh S. ${ }^{1,2}$, Nader Karballaeezadeh ${ }^{3}$, Morteza Mohemmi ${ }^{4}$, \\ Amir Mosavi ${ }^{5,6^{*}}$, and Annamaria R. Varkonyi-Koczy $y^{5,7}$ \\ ${ }^{1}$ Department of Civil Engineering, Ferdowsi University of Mashhad, Mashhad, Iran. \\ ${ }^{2}$ Department of Elite Relations with Industries, Khorasan Construction Engineering Organiza- \\ tion, Mashhad, Iran \\ ${ }^{3}$ Faculty of Civil Engineering, Shahrood University of Technology, Shahrood, Iran \\ ${ }^{4}$ Department of Civil Engineering, Iran University of Science and Technology, Tehran, Iran. \\ ${ }^{5}$ Institute of Automation, Kalman Kando Faculty of Electrical Engineering, Obuda University, \\ 1034 Budapest, Hungary \\ ${ }^{6}$ School of the Built Environment, Oxford Brookes University, Oxford OX3 OBP, UK \\ ${ }^{7}$ Department of Mathematics and Informatics, J. Selye University, Komarno, Slovakia \\ *a.mosavi@brookes.ac.uk
}

\begin{abstract}
Design and advancement of the durable urban train infrastructures are of utmost importance for reliable mobility in the smart cities of the future. Given the importance of urban train lines, tunnels, and subway stations, these structures should be meticulously analyzed. In this research, two-dimensional modeling and analysis of the soil-structure mass of the Alan Dasht station of Mashhad Urban Train are studied. The two-dimensional modeling was conducted using Hashash's method and displacement interaction. After calculating the free-field resonance and side distortion of the soil mass, this resonance was entered into PLAXIS finite element program, and finally, stress and displacement contours together with the bending moment, shear force and axial force curves of the structure were obtained.
\end{abstract}


Keywords: Urban mobility, urban train lines, modeling, soil mass-structure, soil-structure interaction, PLAXIS, computational mechanics, simulation, smart cities, urban sustainable development, urban rail transportation

\section{Introduction}

Today, due to the expansion of cities and urbanization, the need for efficient public transportation is continuously on the rise [1-13]. Among public transport vehicles, the urban train network is of great importance as a standard form of urban rail transportation [14-17]. The construction of the metro network on the ground is less costly, but due to increasing surface congestion, heavy traffic, and scarcity of space, metro lines are mostly built underground [18-20]. On the one hand, due to the low depth of the underground tunnels, metro stations are usually built-in soft soils (i.e., loose surface soils [21-24]). Therefore, much research has been done to provide smart solutions to such problems. Thus, the optimal implementation of these underground spaces and ensuring their security during the long-term construction process is a factor that has been taken into account by designers of underground structures. Among these underground structures, transportation tunnels are of critical importance. Before 1995, tunnels were not designed to tolerate dynamic loads. However, the earthquakes of the 1990s wreaked havoc to some tunnels. For example, the 1999 earthquake in Chi-Chi, Taiwan, damaged the mountain tunnels [25]. Duzce earthquake in Turkey led to the partial destruction of Bolu twin tunnels [26], and Diakia metro station collapsed in Kobe, Japan in 1995 [27]. Sharma and Judd (1990) [28] investigated 192 cases of underground structural behavior in the face of 85 earthquakes worldwide, concluding that the vulnerability of an underground structure could be assessed in terms of the depth of overburden and earthquake parameters of the area. The extent of demolition and damage to tunnels declines 
with an increase in the depth of overburden [29]. In 2001, Hashash [30] noted that the tunnel structure should be considered in terms of plasticity and resistance to earthquake forces [31]. Moreover, to ensure sufficient plasticity in the tunnel cover during an earthquake, the force reduction factor should be equivalent to the tunnel plasticity [32]. In this research, a two-dimensional modeling of the Alan Dasht station of Mashhad Urban Train using Hashash's method along with the displacement interaction at two levels of seismic [33] is performed in PLAXIS software [34], and the results of two-dimensional analysis are presented as displacement and stress contours together with the curves of bending moment, shear force and axial force.

\section{Data}

Line 2 of the Mashhad urban train stretches from the end of the northern Tabarsi Blvd. to the south of Fazl bin Shazan Square with a total length of $12.985 \mathrm{~km}$. The general slope of the ground is from south to north. Alan Dasht station is located between Alan Dasht Square and 9th Koohsangi Street (Edalat) in Mashhad, constituting the 10th station out of 12 stations of this line. The axis of the Alan Dasht station is planned to be positioned at a distance of 10+512.27 on the route of Line 2 of Mashhad urban train. Further, two platforms with a width of about $4 \mathrm{~m}$ and a length of $100 \mathrm{~m}$ on both sides of the railway represent another physical feature of the Alan Dasht station. The station is positioned in a northeast-southwest direction. Concerning the elevation, the station is categorized as the underground type and rails are located at a depth of about $20 \mathrm{~m}$ from the street and $976.89 \mathrm{~m}$ from the sea level. The slope of the project line of the rail is about 0.002 in the station, and in the longitudinal profile, the downward direction of the rail slope is towards the northeast. Figures (1) and (2) show the plan and the top view of the Alan Dasht station. 


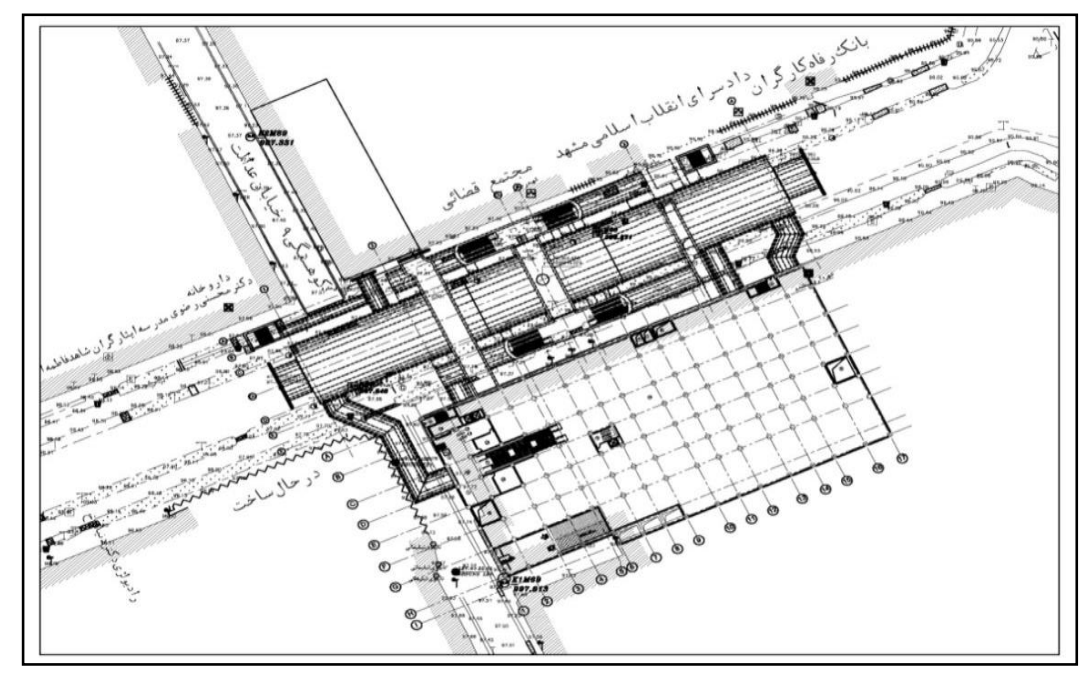

Fig. 1. The plan at the site of the Alan Dasht station

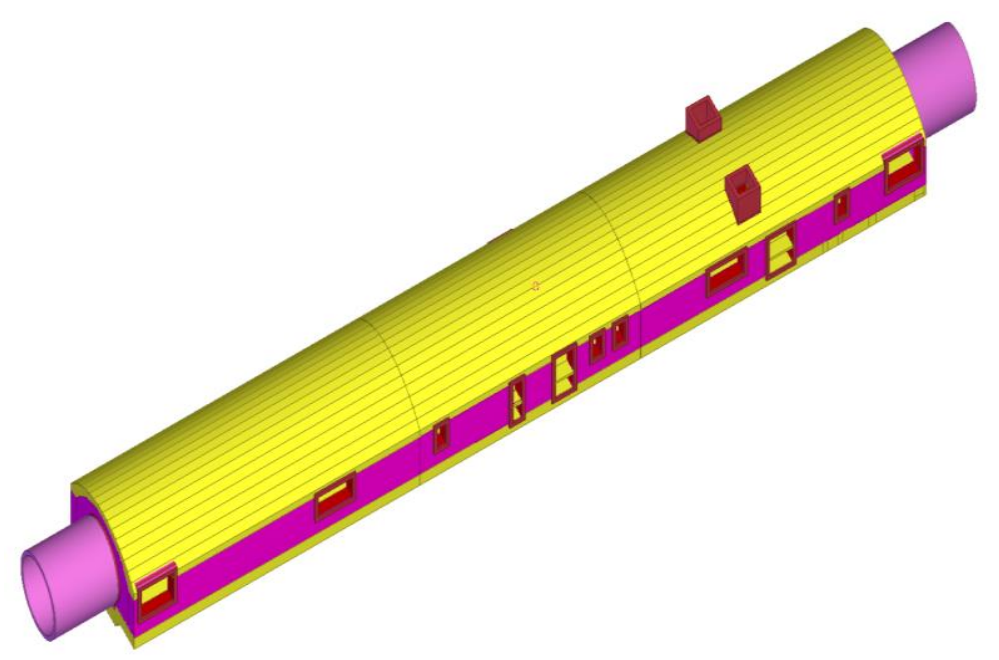

Fig. 2. Top view of Al-Dasht station 


\subsection{Geometry and model specifications}

2 of the Mashhad urban train stretches from the end of the Northern Tabarsi Blvd. to the South of Mashhad.

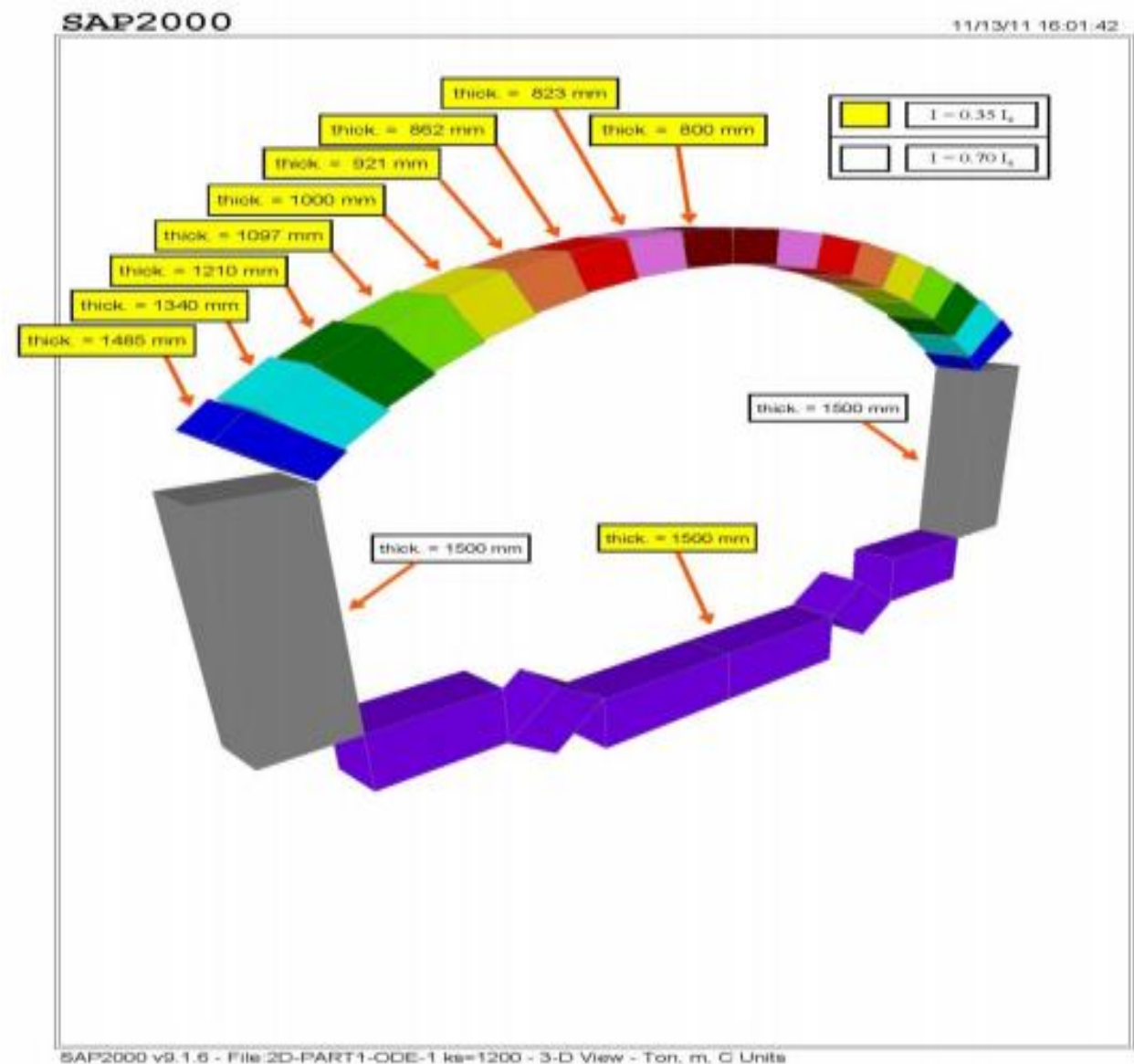

Fig. 3. Two-dimensional model view (MDE earthquake) 
Table 1. Specifications of materials

\begin{tabular}{lll}
\hline Materials & Bar & Concrete \\
\hline Resistance & $\mathrm{F}_{\mathrm{y}}=4000 \mathrm{Mpa}$ & $\mathrm{F}_{\mathrm{c}}=250 \mathrm{Mpa}$ \\
\hline
\end{tabular}

\section{$3 \quad$ Soil-structure modeling}

\subsection{Hashash Method}

The Hashash method [32] is based on imposing an absolute displacement on the structure buried in the soil. According to this method, the resonance of soil mass is determined based on soil seismic parameters [33, 35, 36]. Further, the resonance ratio imposed on the buried structure in the soil relative to the soil mass resonance is determined based on the ratio of structural stiffness to soil hardness, and then this displacement is applied to the structure based on the specific loading pattern. This method complies by the "principals of designing the stations of Line 2 of Mashhad urban train". The geodynamic parameters required in this method to estimate the load on the station are as follows:

1) Propagation velocity of shear wave: The value of $C_{S}$ of soil is determined from the geotechnical report at the site of each station by averaging of figures.

2) Dynamic Shear Modulus of Soil Mass: The dynamic shear modulus of the soil mass [37] should also be determined from geotechnical studies. However, in the absence of this information, dynamic shear modulus can be calculated from Eq. (1): 


$$
G_{m}=\rho \times\left(C_{s}\right)^{2}
$$

The behavior of soil mass around the station is assumed to be linearly elastic, and given the dependence of the dynamic shear modulus on the strain level and normal level of strains during the earthquake, the effective dynamic shear modulus of the soil is estimated as $\mathrm{G}_{\mathrm{e}}=0.6 \mathrm{G}_{\mathrm{m}}$.

3) The maximum shear strain of the original soil mass: The maximum shear strain of the original soil mass, $\boldsymbol{\gamma}_{\text {free-field }}$, is obtained from Eq. (2).

$$
\begin{aligned}
& \gamma_{\text {free-field }} \\
& =\frac{\text { PGV }}{C_{S}}
\end{aligned}
$$

Where PGV is the maximum propagation velocity of soil particles at the depth of the station.

If this parameter is calculated in seismic studies, it can be directly used to compute $\boldsymbol{\gamma}_{\text {free-field }}$. Otherwise, PGV value at the depth of the station can be roughly determined using the following method:

a) PGA calculation in the station depth during the desired return period at the mean depth of the station based on the acceleration distribution graphs in the soil profile.

b) PGV calculation from PGA based on station distance from the fault, type of soil and expected magnitude of the earthquake and its effect on the useful life of the structure according to Table (2). 
Table 2. Variation of "PGV to PGA" ratio with distance from fault and soil type (after Power et al., 1996)

\begin{tabular}{|c|c|c|c|}
\hline \multirow{2}{*}{$\begin{array}{l}\text { Moment magnitude } \\
\left(\mathrm{M}_{\mathrm{W}}\right)\end{array}$} & \multicolumn{3}{|c|}{ Source-to-site distance $(\mathrm{km})$} \\
\hline & $0-20$ & $20-50$ & $50-100$ \\
\hline \multicolumn{4}{|l|}{ Rock $^{a}$} \\
\hline 6.5 & 66 & 76 & 86 \\
\hline 7.5 & 97 & 109 & 97 \\
\hline 8.5 & 127 & 140 & 152 \\
\hline \multicolumn{4}{|l|}{ Stiff soil ${ }^{\text {a }}$} \\
\hline 6.5 & 94 & 102 & 109 \\
\hline 7.5 & 140 & 127 & 155 \\
\hline 8.5 & 180 & 188 & 193 \\
\hline \multicolumn{4}{|l|}{ Soft soil ${ }^{\text {a }}$} \\
\hline 6.5 & 140 & 132 & 142 \\
\hline 7.5 & 208 & 165 & 201 \\
\hline 8.5 & 269 & 244 & 251 \\
\hline
\end{tabular}

In this table, the sediment types represent the following shear wave velocity ranges: rock $\geq 750 \frac{\mathrm{m}}{\mathrm{s}}$, stiff soil $200-750 \frac{\mathrm{m}}{\mathrm{s}}$, soft soil $<200 \frac{\mathrm{m}}{\mathrm{s}}$. The relationship between peak ground velocity and peak ground acceleration is less certain in soft soils.

In the seismic risk analysis of the project, the baseline design earthquake (target earthquake) is defined as 6.8 on the Richter scale in the range of 6.3 to 7.3. However, considering the Shandiz fault as a fault with the seismic potential of up to 7.1 on the Richter scale at a distance of up to $20 \mathrm{~km}$ from the project, 7.1 Richter was determined as the basis for determining the ratio of the wave propagation velocity to the maximum seismic acceleration for the whole baseline project. Thus, we have: 
PGV=122 PGA (for Stiff Soil \& SSD=0-20 km \& Mw=7.1)

The distortion applied to the station is calculated by Eq. (3).

$$
\begin{aligned}
& \gamma_{\text {structure }} \\
& =\mathrm{R} \times \gamma_{\text {free-field }}
\end{aligned}
$$

Where, the coefficient $\mathrm{R}$, which is the ratio of structural distortion to soil environment distortion, is a function of structural stiffness and soil hardness ratio, which is achieved from the displacement interaction method.

\section{$4 \quad$ Displacement interaction method}

In this method, the distortion applied to the underground structure is considered in terms of the structure-soil mass interaction using analytical or semi-analytical methods. In this method, considering the stiffness of the alternative structure relative to soil mass removed from the environment, a good approximation of soil-structure interaction and the distortion applied to the structure during an earthquake is obtained.

For interactive analysis, modeling should be performed in soil-structure interaction software such as PLAXIS [38, 39]. The steps and assumptions of modeling are as follows:

- Two-Dimensional modeling is performed in-plane strain mode.

- The soil environment is assumed to be elastic.

- $\mathrm{G}_{\mathrm{e}}=0.6 \mathrm{Gm}$.

- All tensions, including horizontal and vertical tensions, are assumed equal to zero.

- The width of the model is at least 10 times the width of the structure and its depth is at least one-fourth of the length of the shear wave. 
- The modeling of the final coating structure is carried out using a bending beam element with elastic behavior.

- The connection of structural elements to the soil through interface elements is considered as elasto-plastic with environmental resistance in the static model.

To perform this analysis, it is necessary to construct two computational models which are described below:

\subsection{Original soil model}

In this step, the original soil model, irrespective of the structure, is subject to a compulsory displacement of $\Delta_{\text {free-field }}$, similar to the following figures. (Figures 3 and 4).

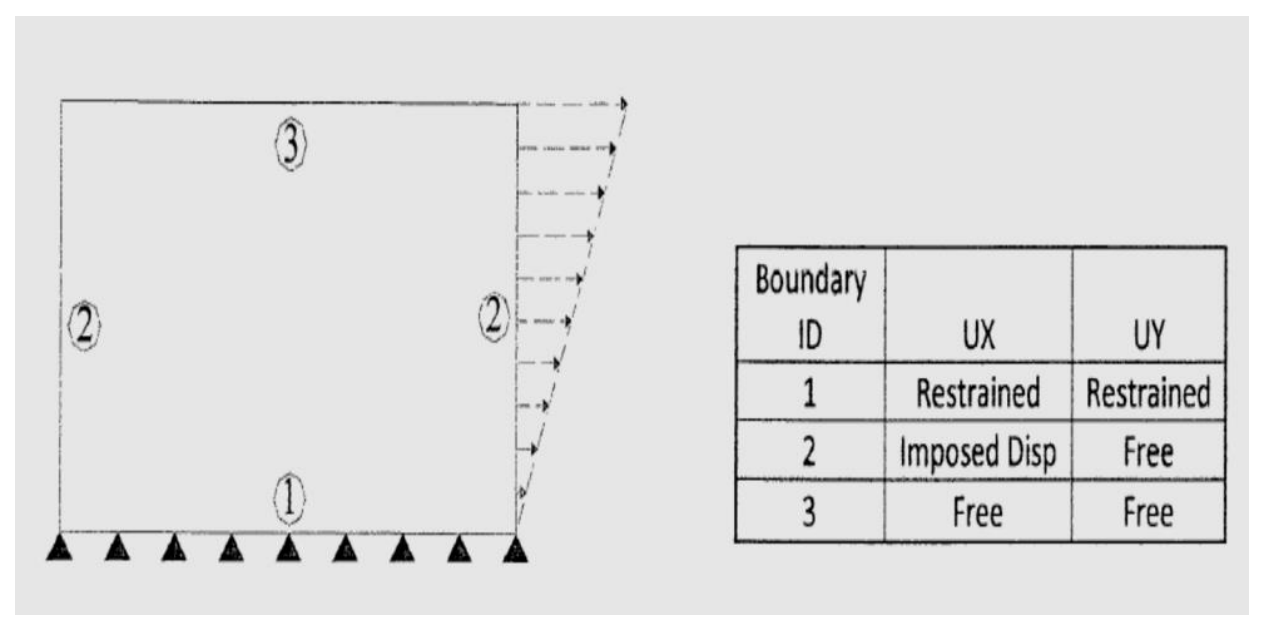

Fig. 4. Boundary conditions of the problem 


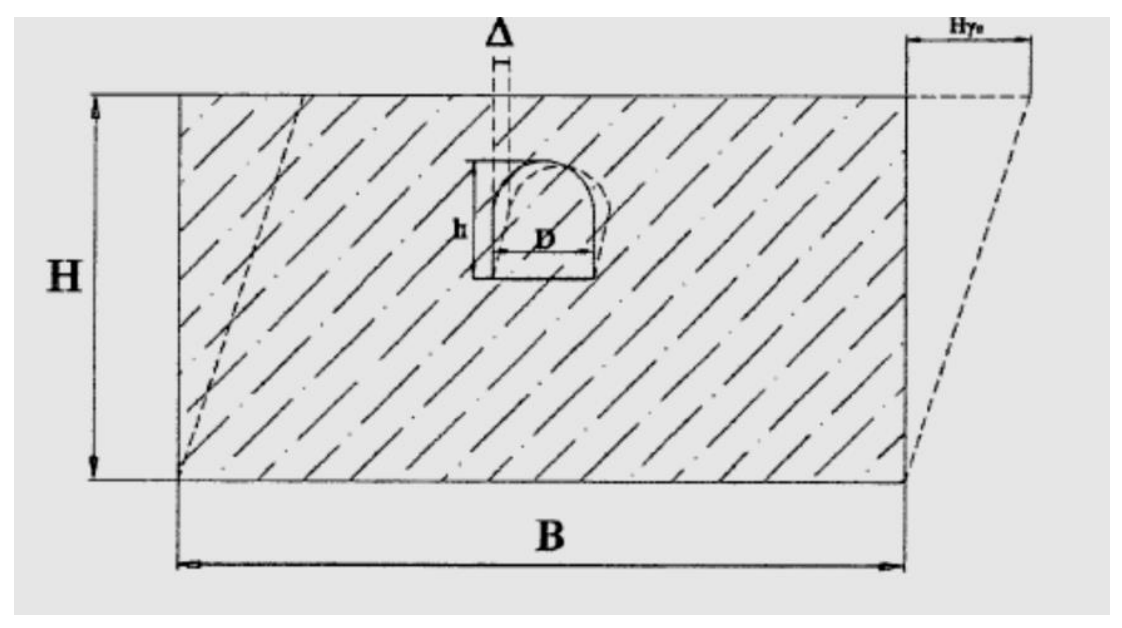

Fig. 5. Compulsory displacement of the structure

The relative displacement of the highest and lowest points of the construction site in the original soil is measured (Eq. 4)

$$
\begin{aligned}
& \gamma=\frac{\Delta}{\mathrm{h}}, \alpha \\
& =\frac{\gamma_{\text {free-field }}}{\gamma}
\end{aligned}
$$

\subsection{Soil-Structure Model}

In this model, soil mass and structure are modeled simultaneously and subjected to a compulsory triangular displacement of size $\alpha \Delta_{\text {free-field }}$ in the vertical boundary of the soil mass, as shown in Fig. 6. 


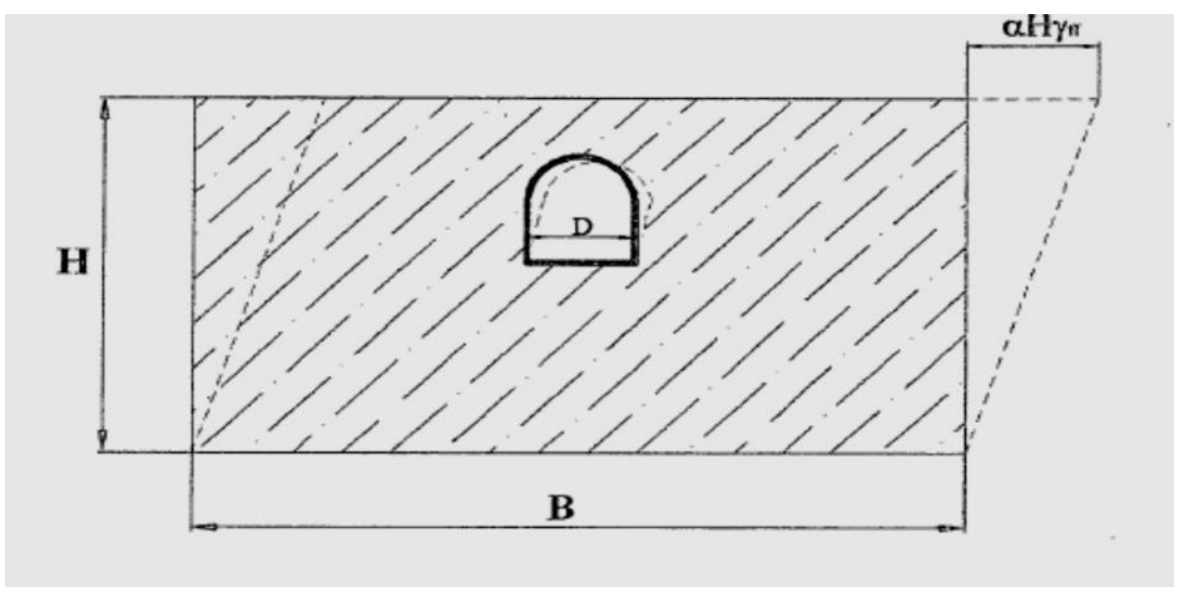

Fig. 6. Compulsory triangular displacement relative to soil mass and structure

By calculating the compulsory displacement imposed on the structure and applying this deformation relative to the depth of the station to one of the loading patterns discussed below, the internal forces for designing the elements of the station structure can be determined. For stations with overheads of $>30 \mathrm{~m}$, the loading pattern in Figure (7.a) and, for stations with overheads of $<30 \mathrm{~m}$, the loading pattern in Figure (7.b) should be used.

(a)

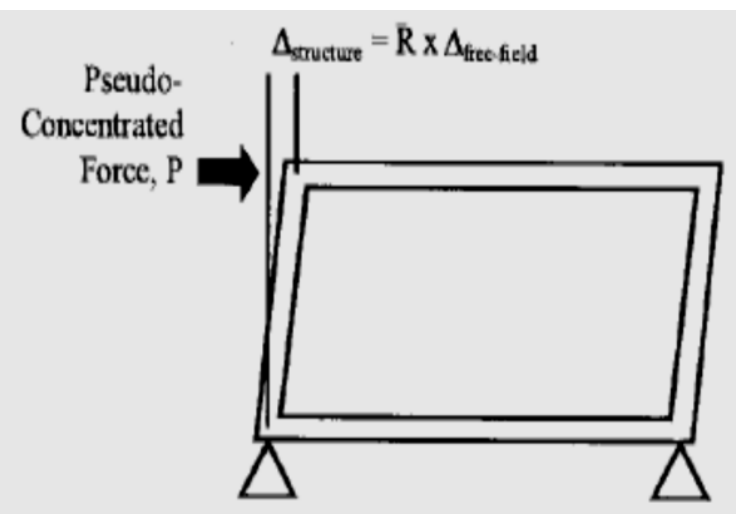




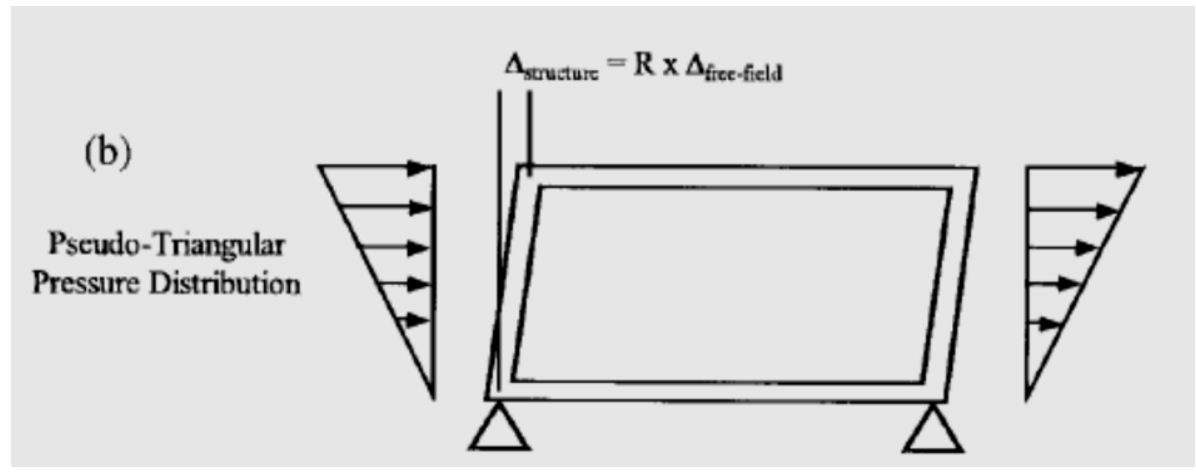

Fig. 7. Types of loading patterns [32]

In the seismic analysis of the structure, the structural analysis is performed with the unit length (for the lateral fixed part of the wall) or with a limited length on both moving sides of the sidewall, and the results are manually merged with the results of static analyses. The reinforcement of the structure is conducted on-site. A 3D modeling of the structure does not correspond to Hashash's assumptions in practice, and rigid performance of the sidewalls of the station will preclude any distortion in the station. The following assumptions will also be considered in the design of structural elements:

- In all analyses, the effective hardness of concrete cross-sections (cracked sections) is used.

- The behavior coefficient of the structure is $\mathrm{R}=1$.

\section{$5 \quad$ Seismic Loading}

The PLAXIS 8.2 [38] software package was used to perform displacement interaction analysis. This software is capable of two-dimensional modeling of drilling steps and installation of a maintenance system relative to the effects of soil-structural interaction. In this program, the numerical solution is the finite 
element, which allows analyzing the continuous environment with linear and elasto-plastic behavior in a plane strain model.

As described earlier, according to the basics of Line 2 of Mashhad Urban Train, two-dimensional modeling was performed in a plane strain mode with an elastic soil environment and $\mathrm{G}_{\mathrm{e}}=0.6 \mathrm{G}_{\mathrm{m}}$. For this modeling, three-node elements were used for the soil environment. All tensions in the model, including horizontal and vertical tensions, were considered to be zero. Also, all modeling was conducted in a single phase. The necessary calculations for the two-dimensional modeling of the Alan Dasht station are described in (5) to (10).

$$
\begin{aligned}
\mathrm{C}_{\mathrm{S}}= & 695 \frac{\mathrm{m}}{\mathrm{s}}, \quad, \quad \rho=2.0 \\
& \mathrm{G}_{\mathrm{m}}=\rho\left(\mathrm{C}_{\mathrm{S}}\right)^{2}=2 \times 695^{2}=966050 \mathrm{kpa} \\
& \mathrm{G}_{\mathrm{e}}=0.6 \mathrm{G}_{\mathrm{m}} \\
& =579630 \mathrm{kpa}
\end{aligned}
$$

In the ODE mode:

$$
\begin{aligned}
& \mathrm{PGA}=0.17, \mathrm{PGV}=122 \mathrm{PGA}=0.207 \frac{\mathrm{m}}{\mathrm{s}} \\
& \gamma_{\text {free-field }}=\frac{\mathrm{PGV}}{\mathrm{C}_{\mathrm{S}}}=\frac{0.207}{695}=2.978 \times 10^{-4}
\end{aligned}
$$

In the MDE mode:

$$
\begin{aligned}
\text { PGA }=0.37, \mathrm{PGV} & =122 \mathrm{PGA} \\
= & 0.45 \frac{\mathrm{m}}{\mathrm{s}} \\
\gamma_{\text {free-field }}=\frac{\mathrm{PGV}}{\mathrm{C}_{\mathrm{S}}} & =\frac{0.45}{695} \\
= & 6.455 \times 10^{-4}
\end{aligned}
$$


The dimensions of the model should be chosen in a way to model the environment with good approximation. For this purpose, the width of the environment was assumed to be 10 times the width of the structural cross-section. The depth of the model was considered to be at least one-fourth of the length of the shear wave. The station structure and retaining structure were modeled using the bending beam element with elastic behavior. Also, the casing was modeled in the cracked form. The boundary conditions of the model were applied as shown below.

\section{Boundary conditions}

In Fig. 8 and Table 3, the boundary conditions of the modeled sample are shown.

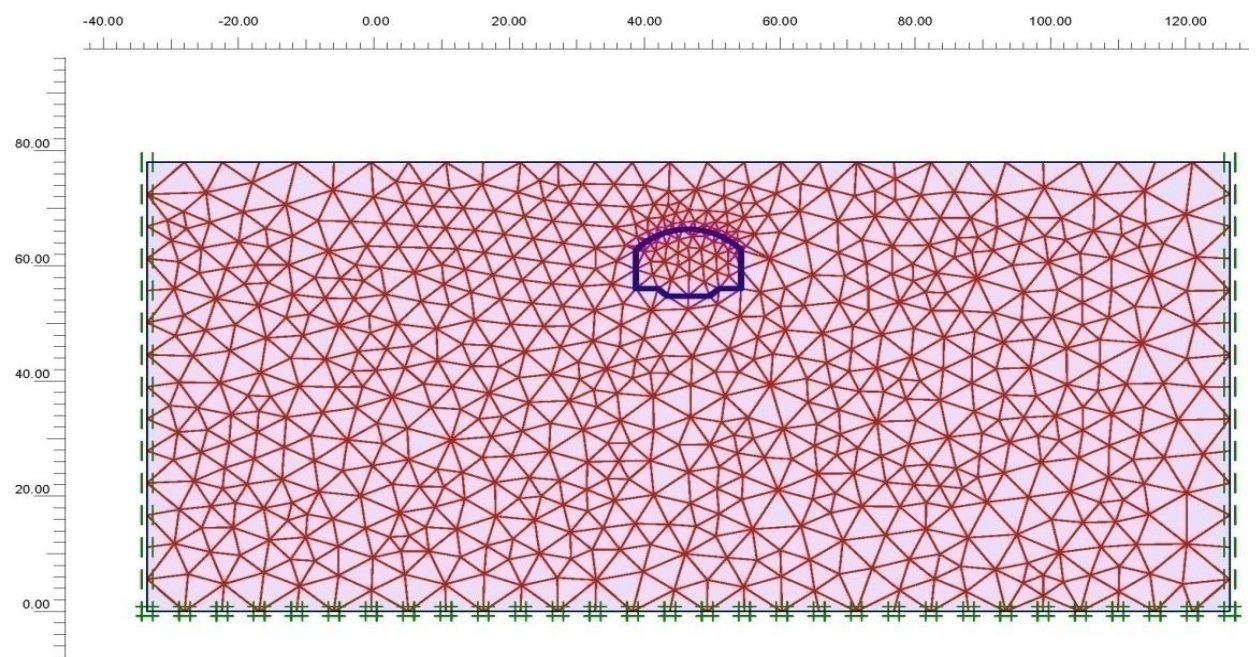

Fig. 8. How to apply boundary conditions on a two-dimensional model 
Table 3. Model boundary conditions

\begin{tabular}{clc}
\hline Boundary ID & $\mathrm{U}_{\mathrm{x}}$ & $\mathrm{U}_{\mathrm{y}}$ \\
\hline 1 & Restrained & $\begin{array}{c}\text { Re- } \\
\text { strained }\end{array}$ \\
\hline 2 & Imposed Displacement & Free \\
\hline 3 & Free & Free \\
\hline
\end{tabular}

\section{$7 \quad$ Results of Analysis}

In this section, the results of the analysis of two-dimensional modeling of soilstructure are discussed. According to the resonances obtained in the ODE model $\left(\gamma_{\text {free-field }}=6.455 \times 10^{-4}\right)$ and $\operatorname{MDE}\left(\gamma_{\text {free-field }}=2.978 \times 10^{-4}\right)$ in Section 5, the soil mass was subject to these resonances, Figures (9) and (10) reveal the application of side displacement to the soil mass in PLAXIS software under ODE and MDE seismic conditions. In Figures (11) and (12), the deformation of the meshed soil mass is observed under both ODE and MDE seismic conditions. For more meticulous analysis, stress and deformation graphs should be extracted. In Figures (13) and (14), the displacement contours of free-field soil masses are observed under ODE and MDE seismic conditions. As can be seen, the maximum displacements are observed in the upper angles, with values reaching $54.18 \mathrm{~mm}$ in the ODE and $108.36 \mathrm{~mm}$ in the MDE seismic conditions. Also, according to the mean stress contours derived from the analysis, as shown in Figures (15) and (16), the maximum average stress in soil mass is 1490 $\mathrm{KN} / \mathrm{m} 2$ under ODE and maximum stress in soil mass is about $2840 \mathrm{KN} / \mathrm{m} 2$ under MDE seismic conditions. After analyzing the soil-structure model underside distortion, the bending moment, shear force, and axial force curves were obtained. In Figures (17) and (18), which exhibit the bending moment curves 
under both ODE and MDE seismic conditions, the maximum bending moment was 1580 KN.m and 2670KN.m in the ODE and MDE modes. Figures 19 and 20 illustrate the sheer force curves and Figures (20) and (21) depict axial force curves of the structure under ODE and MDE conditions. In these curves, the maximum shear force and the maximum axial force are $2000 \mathrm{KN}$ and $2330 \mathrm{KN}$, respectively.

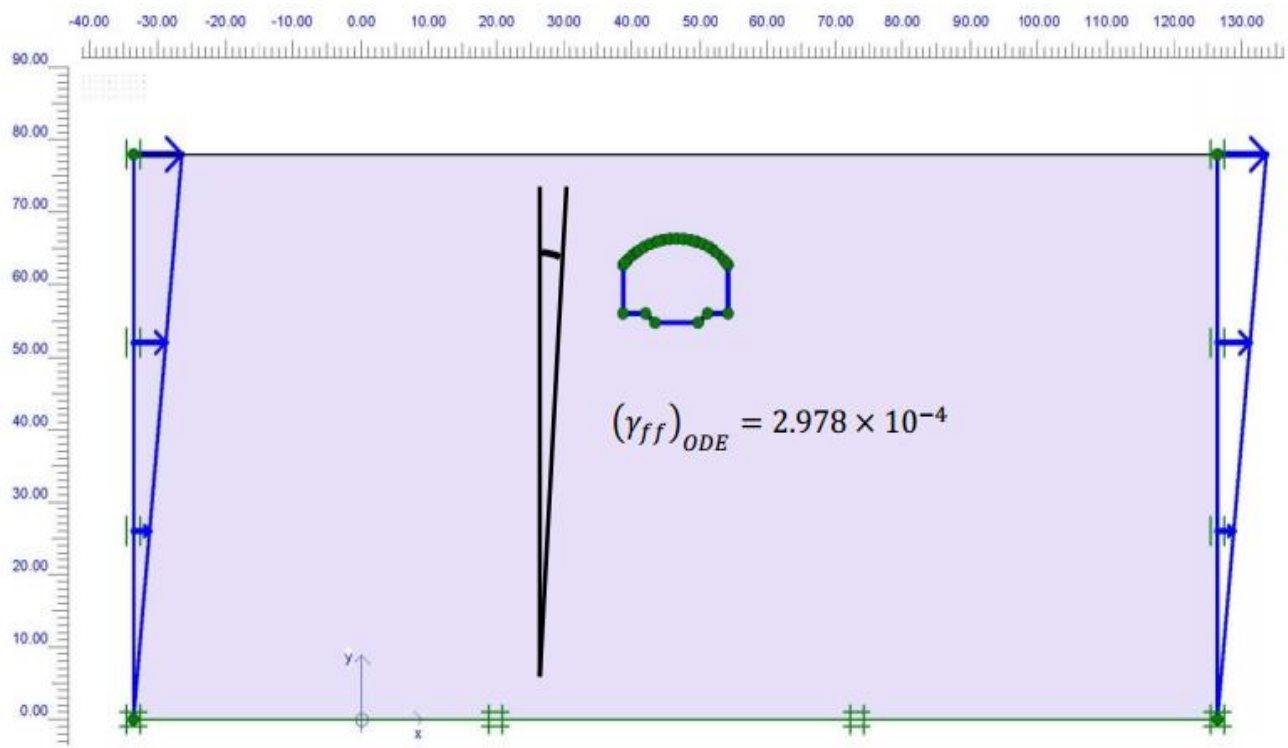

Fig. 9. Two-dimensional model the free-field soil mass in ODE mode 


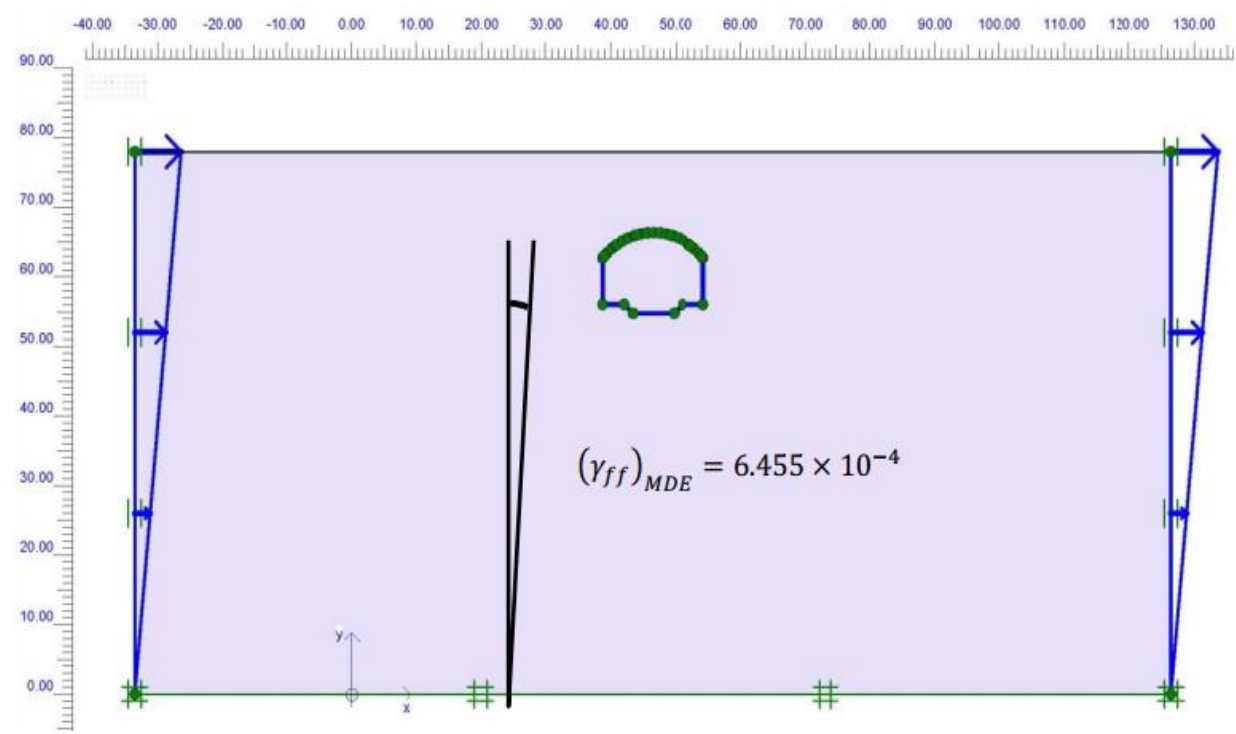

Fig. 10. Two-dimensional model of applying the free-field soil mass in MDE mode

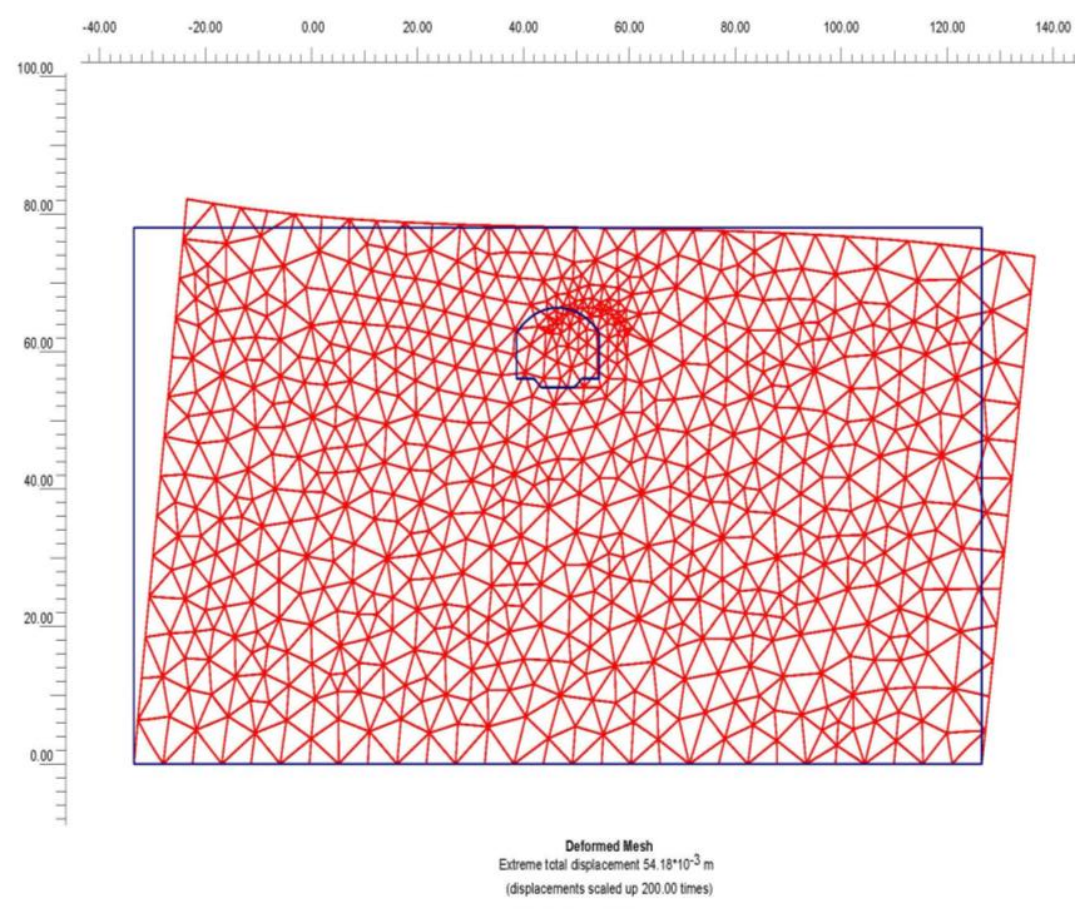


Fig. 11. Modified displacement model of free field soil mass in ODE mode

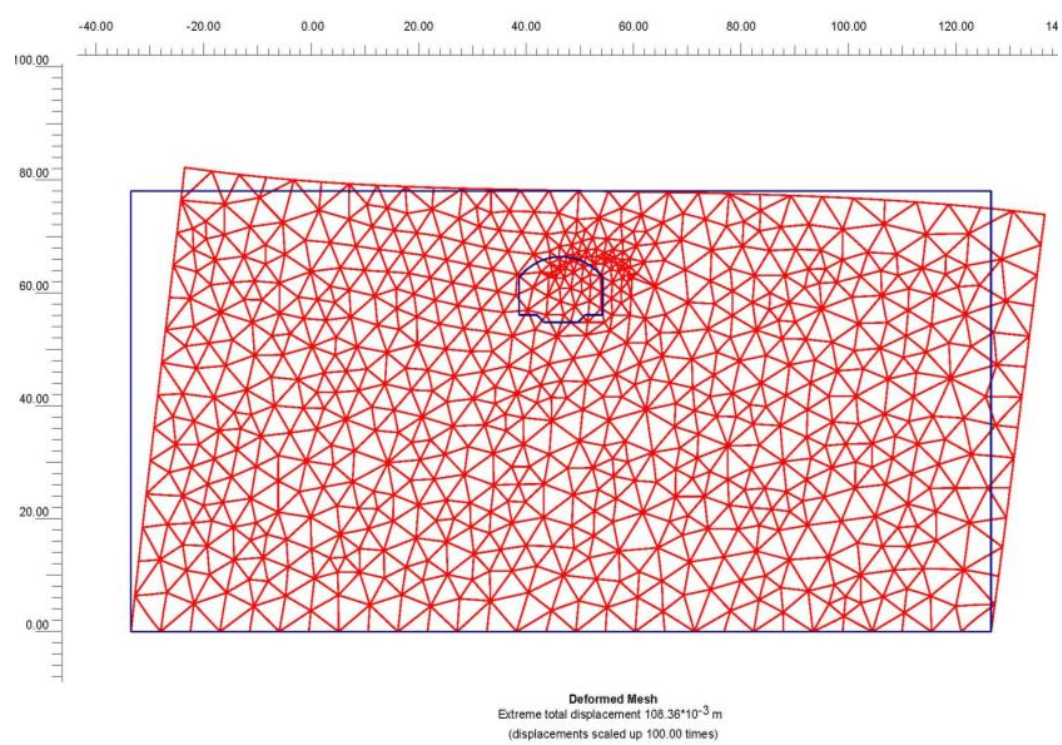

Fig. 12. Modified displacement model of free field soil mass in MDE mode

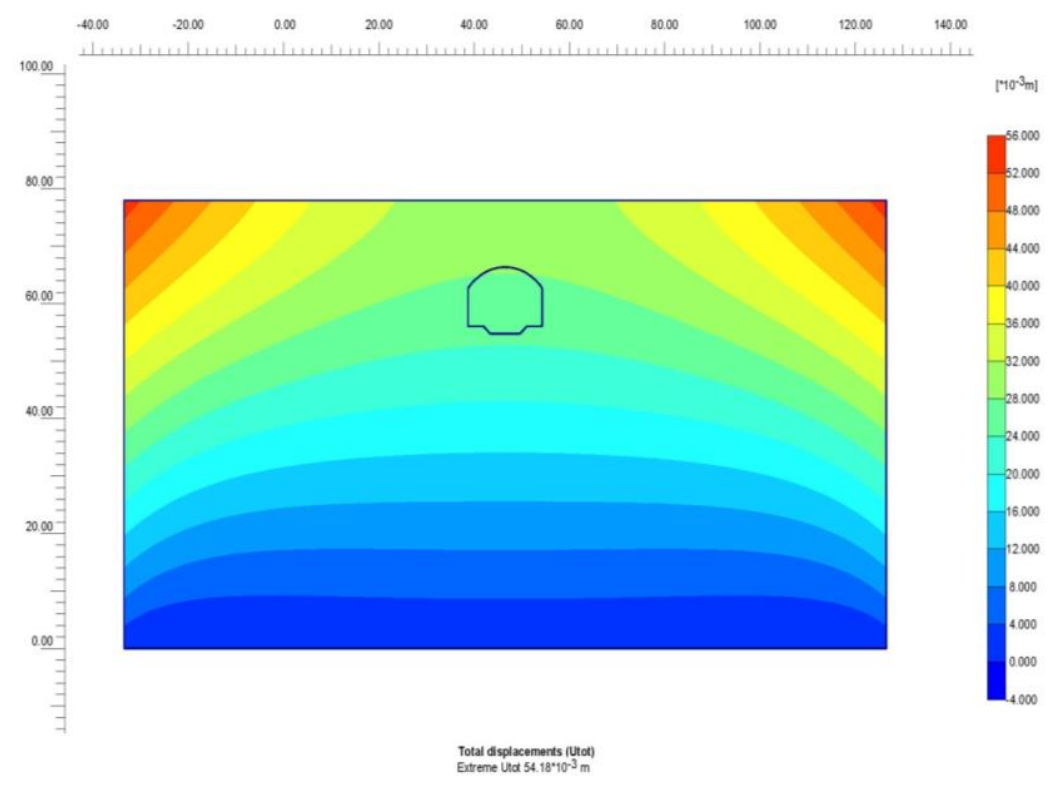

Fig. 13. Displacement contour of the free-field soil mass in ODE mode 


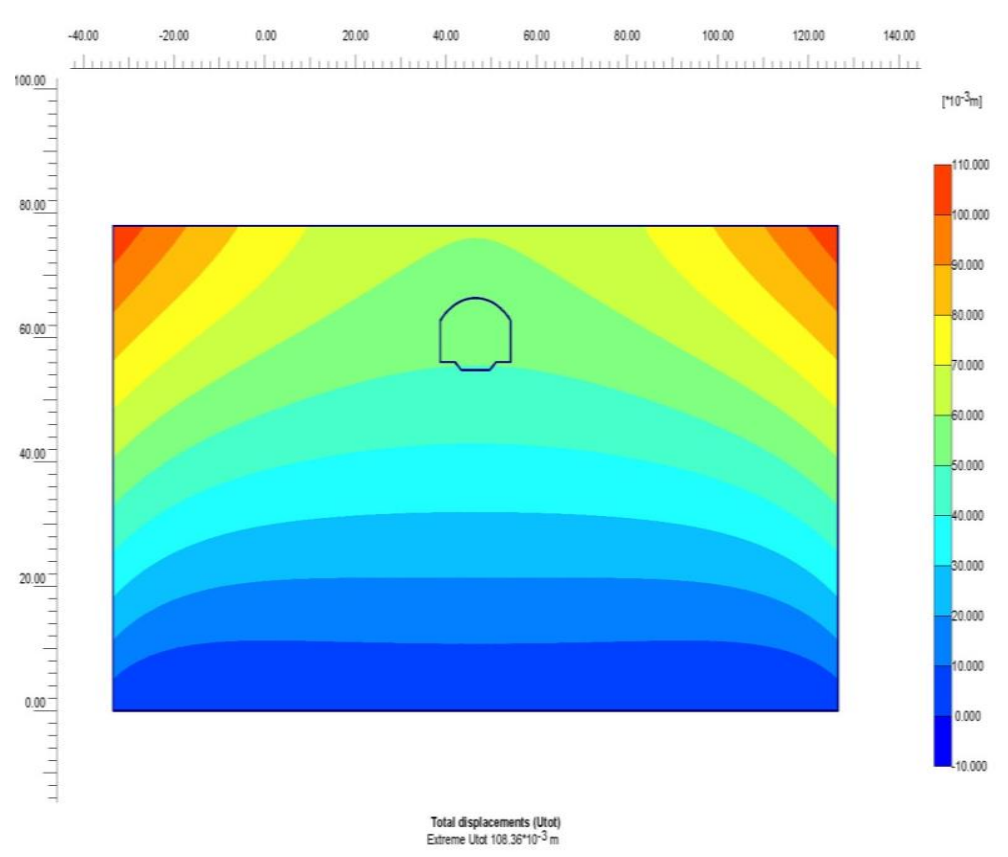

Fig. 14. Displacement contour of the free-field soil mass in MDE mode

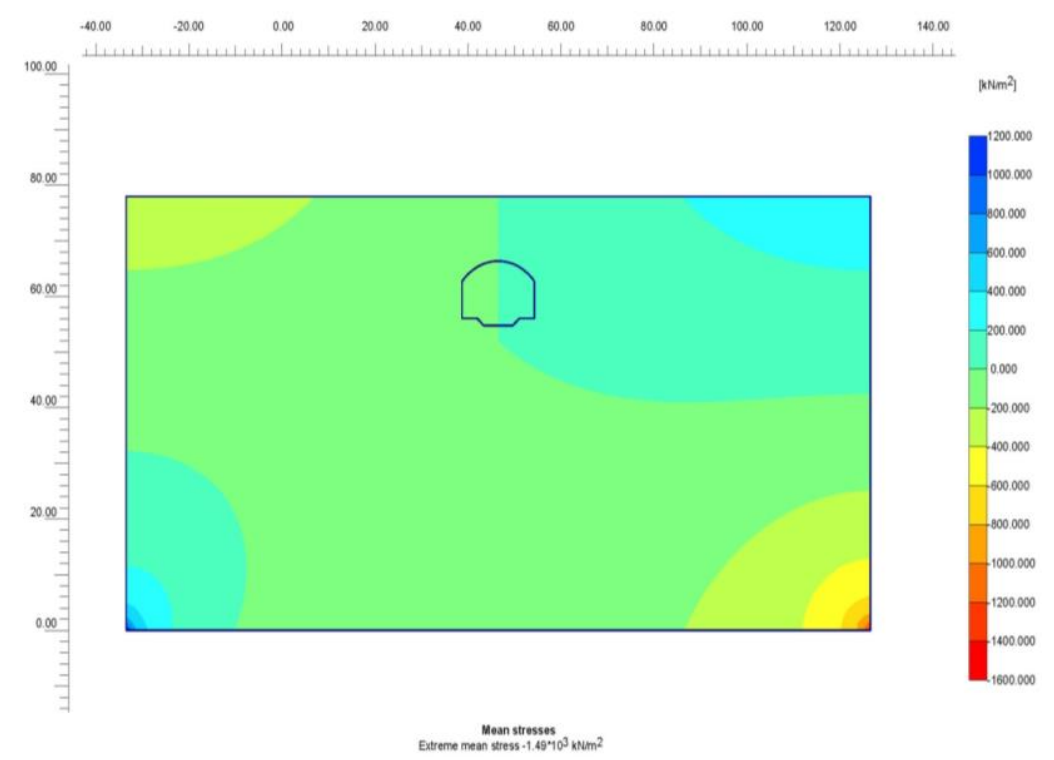

Fig. 15. Medium stress contour in free-field soil mass in ODE mode 


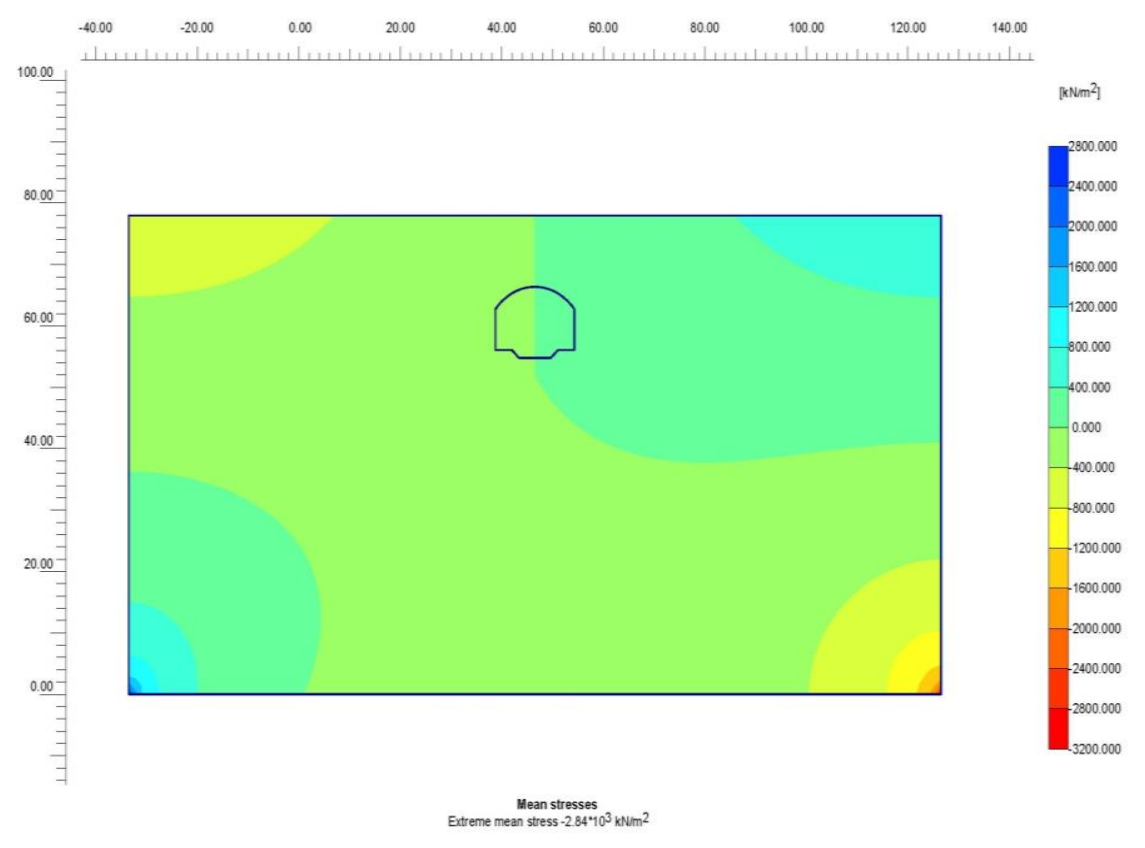

Fig. 16. Medium stress contour in free-field soil mass in MDE mode

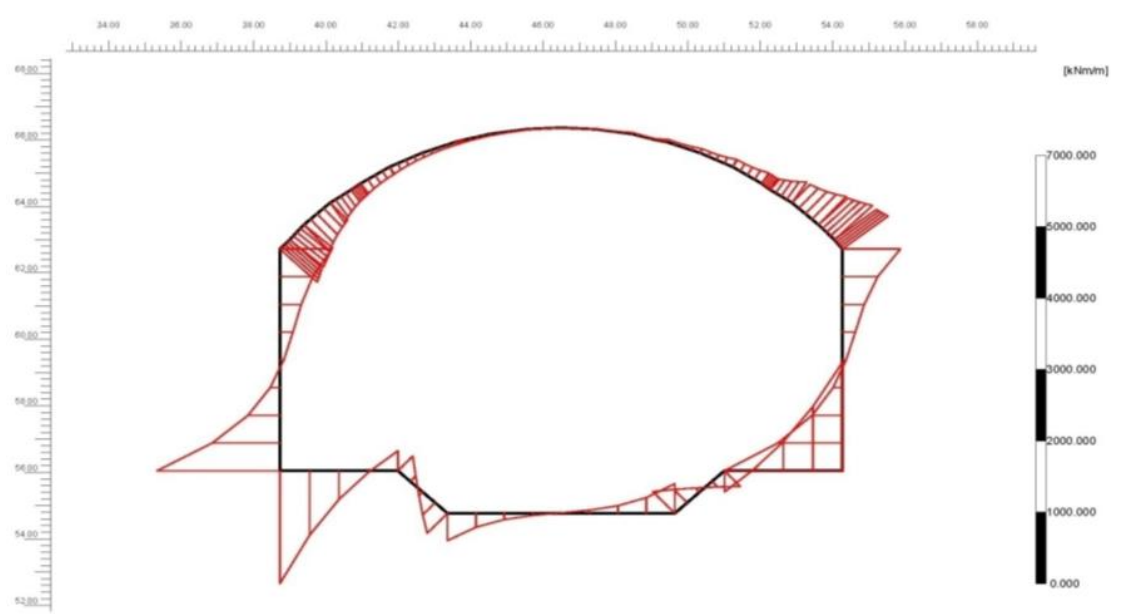

Fig. 17. Diagram of the main structure moments (without coefficient) under the impact of side distortion of soil-structure in ODE mode 


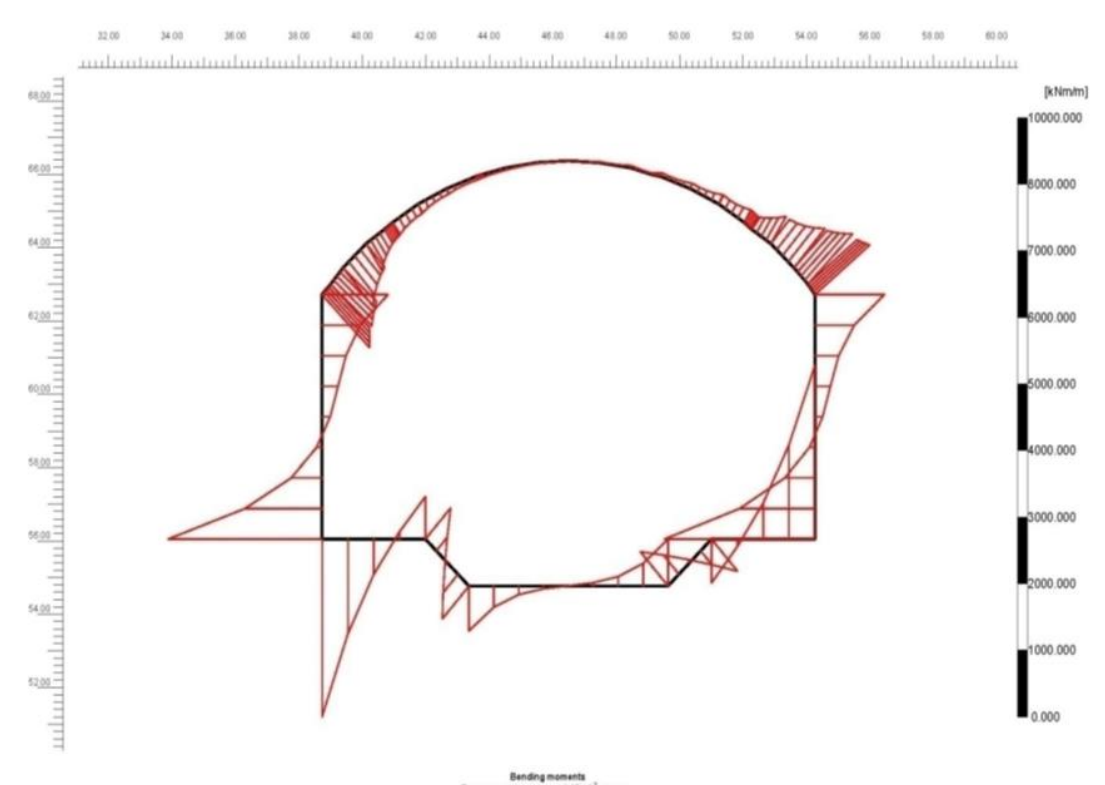

Fig. 18. Diagram of the main structure moments (without coefficient) under the impact of side distortion of soil-structure in MDE mode

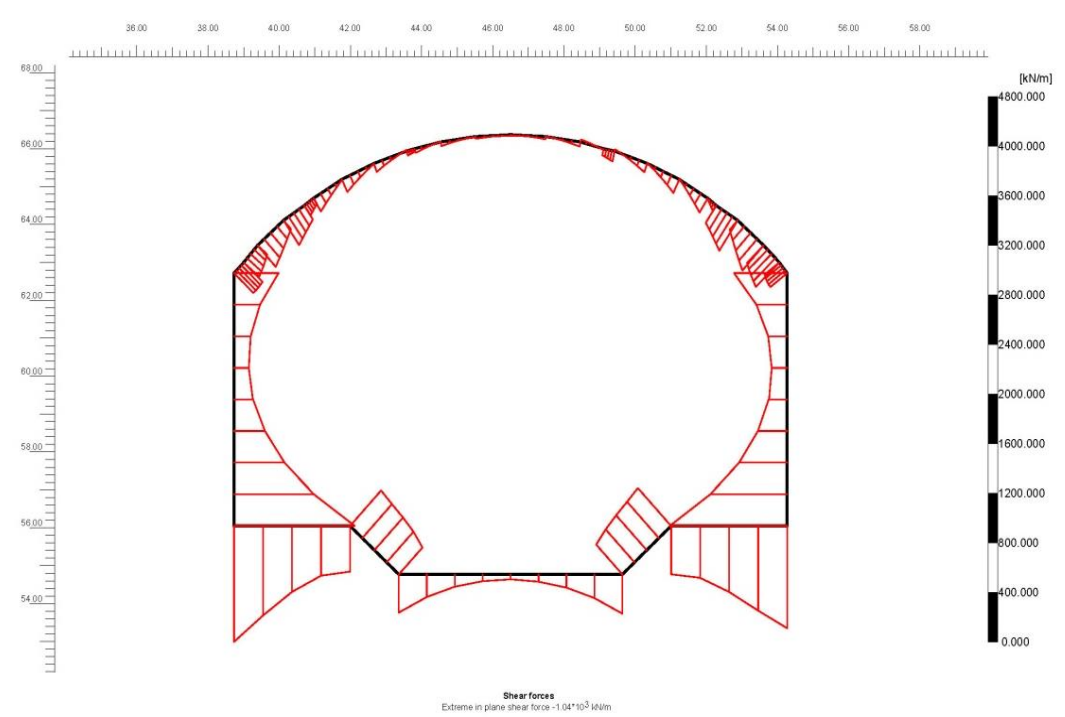

Fig. 19. Shear diagram of the main structure (without coefficient) under the impact of side distortion of soil-structure in ODE mode 


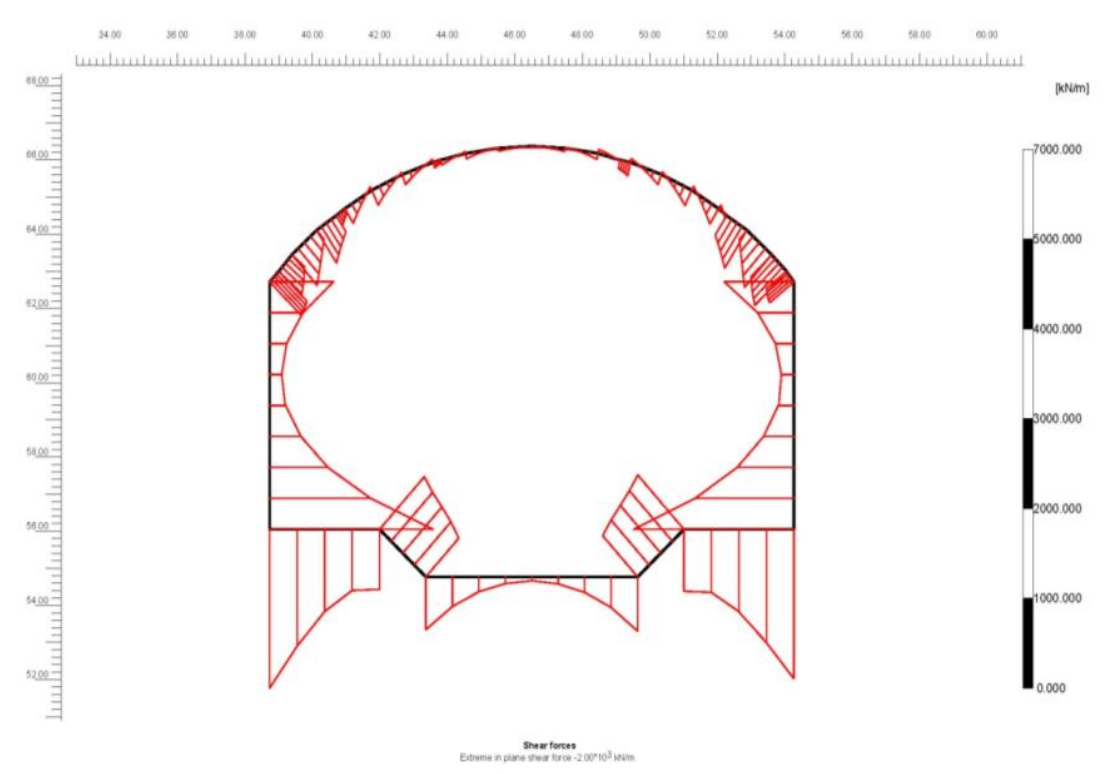

Fig. 20. Shear diagram of the main structure (without coefficient) under the impact of side distortion of soil-structure in MDE mode

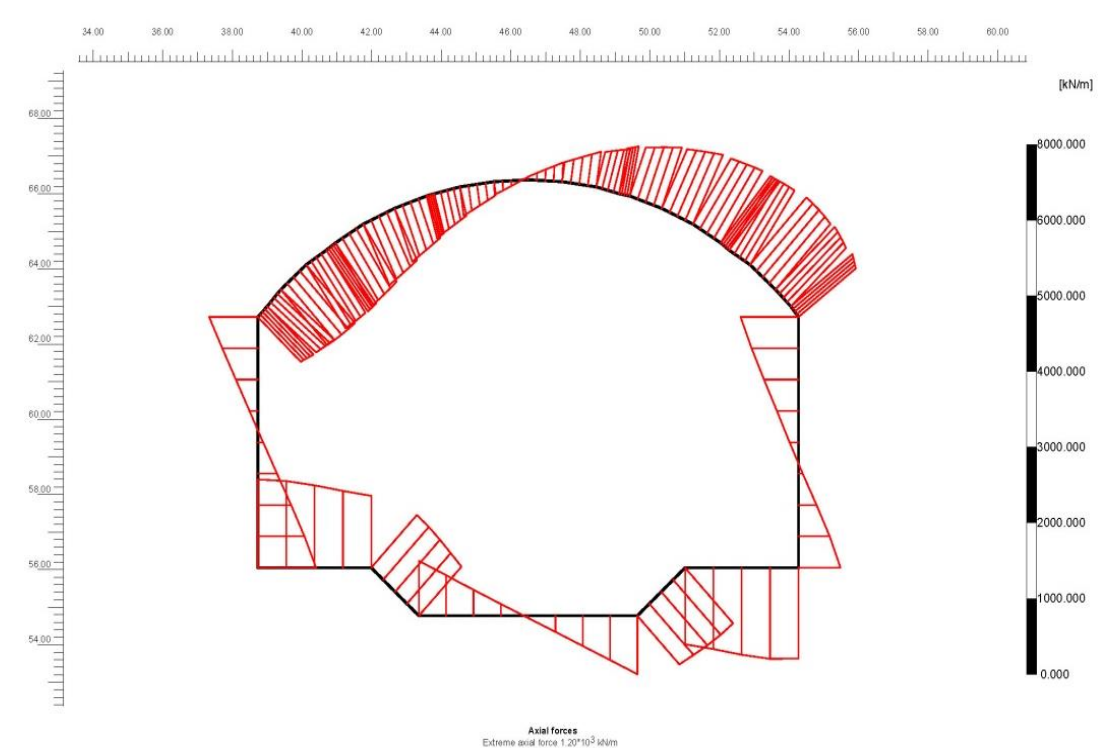

Fig. 21. Axial force (of the main structure (without coefficient) under the impact of side distortion of soil-structure in MDE mode 


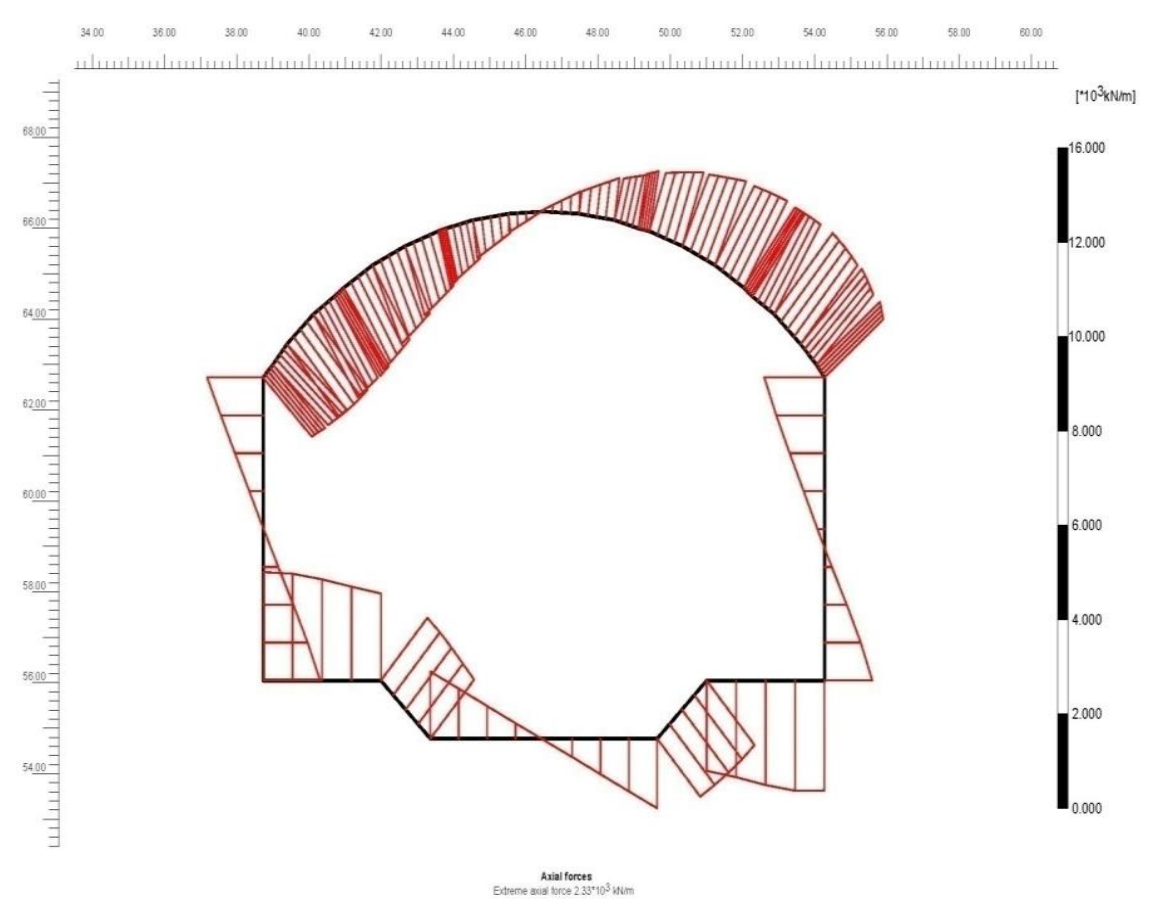

Fig. 22. The axial force of the main structure (without coefficient) under the impact of side distortion of soil -structure in MDE mode

\section{Conclusion}

In this research, two-dimensional analysis of the soil-structure of Alan Dasht station of the Mashhad Urban Train was conducted. The modeling was performed using PLAXIS finite element program, Hashash and displacement interaction methods for the modeling of soil mass- structure. In these methods, the free-field resonance and side distortion of the soil mass under ODE and MDE seismic conditions were obtained and then applied to a soil mass in accordance with the triangular load pattern. Then, under free-space resonance, the displacement and stress contours in the soil mass were achieved and underside distortion, bending moment, shear force and axial force of the structure were 
achieved. As indicated by the results, the maximum soil mass displacement $(108.36 \mathrm{~mm})$ and maximum soil mass stress $\left(2840 \mathrm{KN} / \mathrm{m}^{2}\right)$ were recorded under MDE earthquake. Moreover, the bending moment, shear force and axial force curves were calculated from the soil mass analysis under side distortion, with maximum values of $2670 \mathrm{KN} . \mathrm{m}, 2000 \mathrm{KN}$ and 2330KN under MDE seismic conditions, respectively. For the future works, the application of artificial intelligence methods such as machine learning and deep learning methods can highly improve the quality of modeling in prediction of the optimal configurations [40-61]. In particular, the hybrid and ensemble machine learning methods are reported to provide higher performance [62-71].

\section{Acknowledgments}

This publication has been supported by the Project: "Support of research and development activities of the J. Selye University in the field of Digital Slovakia and creative industry" of the Research \& Innovation Operational Programme (ITMS code: NFP313010T504) co-funded by the European Regional Development Fund.

\section{Refrences}

1. Aguirre, E., et al., Design and Implementation of Context Aware Applications with Wireless Sensor Network Support in Urban Train Transportation Environments. IEEE Sensors Journal, 2017. 17(1): p. 169-178.

2. Bu, B., et al., Research on Method of Cooperation among Trains for Energy Saving in Urban Rail Transportation. Tiedao Xuebao/Journal of the China Railway Society, 2018. 40(8): p. 43-51. 
3. Fernández-Rodríguez, A., et al., Energy efficiency and integration of urban electrical transport systems: EVS and metro-trains of two real European lines. Energies, 2019. 12(3).

4. He, W., et al., Effect of wind barrier's height on train-bridge system aerodynamic characteristic of cable-stayed bridge for urban railway transportation. Zhongnan Daxue Xuebao (Ziran Kexue Ban)/Journal of Central South University (Science and Technology), 2017. 48(8): p. 2238-2244.

5. Kim, K., Exploring the difference between ridership patterns of subway and taxi: Case study in Seoul. Journal of Transport Geography, 2018. 66: p. 213-223.

6. Tang, T., et al., VISOS: A Visual Interactive System for SpatialTemporal Exploring Station Importance Based on Subway Data. IEEE Access, 2018. 6: p. 42131-42141.

7. Wang, J., et al., IS2Fun: Identification of Subway Station Functions Using Massive Urban Data. IEEE Access, 2017. 5: p. 27103-27113.

8. Aram, F., et al., Design and validation of a computational program for analysing mental maps: Aram mental map analyzer. Sustainability (Switzerland), 2019. 11(14).

9. Dehghani, M., et al., Prediction of hydropower generation using Grey wolf optimization adaptive neuro-fuzzy inference system. Energies, 2019. 12(2).

10. Mosavi, A., et al., State of the art of machine learning models in energy systems, a systematic review. Energies, 2019. 12(7). 
11. Nosratabadi, S., et al., Sustainable business models: A review. Sustainability (Switzerland), 2019. 11(6).

12. Taherei Ghazvinei, P., et al., Sugarcane growth prediction based on meteorological parameters using extreme learning machine and artificial neural network. Engineering Applications of Computational Fluid Mechanics, 2018. 12(1): p. 738-749.

13. Torabi, M., et al., A Hybrid clustering and classification technique for forecasting short-term energy consumption. Environmental Progress and Sustainable Energy, 2019. 38(1): p. 66-76.

14. Nosratabadi, S., et al., Sustainable business models: A review. Sustainability, 2019. 11(6): p. 1663.

15. Peng, Y.T., Z.C. Li, and K. Choi, Transit-oriented development in an urban rail transportation corridor. Transportation Research Part B: Methodological, 2017. 103: p. 269-290.

16. Wu, C., Y. Pei, and J. Gao, Analysis on Transportation Supply-demand Adjustment Ability of Urban Rail Transit Network. Wuhan Ligong Daxue Xuebao (Jiaotong Kexue Yu Gongcheng Ban)/Journal of Wuhan University of Technology (Transportation Science and Engineering), 2017. 41(1): p. 22-26 and 31.

17. Zhang, C., H. Xia, and Y. Song, Rail Transportation Lead Urban Form Change: A Case Study of Beijing. Urban Rail Transit, 2017. 3(1): p. 1522. 
18. Lee, Y., et al., Generation characteristics of nanoparticles emitted from subways in operation. Aerosol and Air Quality Research, 2018. 18(9): p. 2230-2239.

19. Liu, X., et al., Evaluation of the utility efficiency of subway stations based on spatial information from public social media. Habitat International, 2018. 79: p. 10-17.

20. Zhao, X., et al., Clustering Analysis of Ridership Patterns at Subway Stations: A Case in Nanjing, China. Journal of Urban Planning and Development, 2019. 145(2).

21. Liu, X., et al., Evaluation of Effects of Static Pile Driving on Existing Metro Tunnel Structure. Journal of Performance of Constructed Facilities, 2019. 33(4).

22. Mostafaei, M., A.H. Rezaei Far, and A. Rastegarnia, Assessment of the impact of case parameters affecting abrasion and brittleness factors in alluviums of line 2 of theTabriz subway, Iran. Bulletin of Engineering Geology and the Environment, 2019. 78(5): p. 3851-3861.

23. Zhou, S., et al., An Approach Integrating Dimensional Analysis and Field Data for Predicting the Load on Tunneling Machine. KSCE Journal of Civil Engineering, 2019. 23(7): p. 3180-3187.

24. Mosleh, A., S. Nosratabadi, and P. Bahrami, Recognizing the business models types in tourism agencies: utilizing the cluster analysis. International Business Research, 2015. 8(2): p. 173. 
25. Wang, W., et al., Assessment of damage in mountain tunnels due to the Taiwan Chi-Chi earthquake. Tunnelling and underground space technology, 2001. 16(3): p. 133-150.

26. Kontogianni, V.A. and S.C. Stiros, Earthquakes and seismic faulting: effects on tunnels. Turkish Journal of Earth Sciences, 2003. 12(1): p. 153-156.

27. Tajiri, M., Damage done by the great earthquake disaster of the Hanshin. Awaji district to the Kobe municipal subway system and restoration works of the damage. Japanese railway engineering, 1997. 36(2): p. 19-23.

28. Sharma, S. and W.R. Judd, Underground opening damage from earthquakes. Engineering geology, 1991. 30(3-4): p. 263-276.

29. Hashash, Y.M., et al., Seismic design and analysis of underground structures. Tunnelling and underground space technology, 2001. 16(4): p. 247-293.

30. Hashash, Y.M. and D. Park, Non-linear one-dimensional seismic ground motion propagation in the Mississippi embayment. Engineering Geology, 2001. 62(1-3): p. 185-206.

31. Pakbaz, M.C. and A. Yareevand, 2-D analysis of circular tunnel against earthquake loading. Tunnelling and Underground Space Technology, 2005. 20(5): p. 411-417.

32. Hashash, Y.M., et al., Ovaling deformations of circular tunnels under seismic loading, an update on seismic design and analysis of 
underground structures. Tunnelling and Underground Space Technology, 2005. 20(5): p. 435-441.

33. Wang, J.-N. and G. Munfakh, Seismic design of tunnels. Vol. 57. 2001: WIT Press.

34. Plaxis, B., Finite element code for soil and rock analysis. Users Manual, Version, 2000. 7.

35. Karballaeezadeh, N., et al., Prediction of remaining service life of pavement using an optimized support vector machine (case study of Semnan-Firuzkuh road). Engineering Applications of Computational Fluid Mechanics, 2019. 13(1): p. 188-198.

36. Mohammadzadeh, S., et al., Prediction of Compression Index of FineGrained Soils Using a Gene Expression Programming Model. Infrastructures, 2019. 4(2): p. 26.

37. Haase, D., et al., Global Urbanization. The Urban Planet: Knowledge Towards Sustainable Cities, 2018. 19.

38. Brinkgreve, R., et al., PLAXIS 2D 2010. User manual, Plaxis bv, 2010.

39. Manual, P., Finite element code for soil and rock analysis. Published and distributed by AA Balkema Publishers, Nederland's Comput. Geotech, 2007. 32(5): p. 326-339.

40. Asadi, E., et al., Groundwater Quality Assessment for Drinking and Agricultural Purposes in Tabriz Aquifer, Iran. 2019.

41. Asghar, M. Z.; Subhan, F.; Imran, M.; Kundi, F.M.; Shamshirband, S.; Mosavi, A.; Csiba, P.; R. Várkonyi-Kóczy, A. Performance Evaluation 
of Supervised Machine Learning Techniques for Efficient Detection of Emotions from Online Content. Pre-prints 2019, 2019080019 (doi: 10.20944/preprints201908.0019.v1).

42. Bemani, A.; Baghban, A.; Shamshirband, S.; Mosavi, A.; Csiba, P.; Várkonyi-Kóczy, A.R. Applying ANN, ANFIS, and LSSVM Models for Estimation of Acid Sol-vent Solubility in Supercritical CO2. Preprints 2019, 2019060055 (doi: 10.20944/preprints201906.0055.v2).

43. Choubin, B., et al., Snow avalanche hazard prediction using machine learning methods. Journal of Hydrology, 2019. 577.

44. Choubin, B., et al., An ensemble prediction of flood susceptibility using multivariate discriminant analysis, classification and regression trees, and support vector machines. Science of the Total Environment, 2019. 651: p. 2087-2096.

45. Dineva, A., et al., Multi-Label Classification for Fault Diagnosis of Rotating Electrical Machines. 2019.

46. Ghalandari, M., et al., Investigation of submerged structures'flexibility on sloshing frequency using a boundary element method and finite element analysis. Engineering Applications of Computational Fluid Mechanics, 2019. 13(1): p. 519-528.

47. Ghalandari, M., et al., Flutter speed estimation using presented differential quadrature method formulation. Engineering Applications of Computational Fluid Mechanics, 2019. 13(1): p. 804-810. 
48. Mosavi, A. and M. Edalatifar, A Hybrid Neuro-Fuzzy Algorithm for Prediction of Reference Evapotranspiration, in Lecture Notes in Networks and Systems. 2019, Springer. p. 235-243.

49. Mosavi, A., P. Ozturk, and K.W. Chau, Flood prediction using machine learning models: Literature review. Water (Switzerland), 2018. 10(11).

50. Mosavi, A. and T. Rabczuk, Learning and intelligent optimization for material design innovation, D.E. Kvasov, et al., Editors. 2017, Springer Verlag. p. 358-363.

51. Mosavi, A., T. Rabczuk, and A.R. Varkonyi-Koczy, Reviewing the novel machine learning tools for materials design, D. Luca, L. Sirghi, and C. Costin, Editors. 2018, Springer Verlag. p. 50-58.

52. Mosavi, A., et al., Prediction of multi-inputs bubble column reactor using a novel hybrid model of computational fluid dynamics and machine learning. Engineering Applications of Computational Fluid Mechanics, 2019. 13(1): p. 482-492.

53. Mosavi, A. and A.R. Varkonyi-Koczy, Integration of machine learning and optimization for robot learning, R. Jablonski and R. Szewczyk, Editors. 2017, Springer Verlag. p. 349-355.

54. Qasem, S.N., et al., Estimating daily dew point temperature using machine learning algorithms. Water (Switzerland), 2019. 11(3).

55. Rezakazemi, M., A. Mosavi, and S. Shirazian, ANFIS pattern for molecular membranes separation optimization. Journal of Molecular Liquids, 2019. 274: p. 470-476. 
56. Riahi-Madvar, H., et al., Comparative analysis of soft computing techniques RBF, MLP, and ANFIS with MLR and MNLR for predicting grade-control scour hole geometry. Engineering Applications of Computational Fluid Mechanics, 2019. 13(1): p. 529-550.

57. Shabani, S.; Samadianfard, S.; Taghi Sattari, M.; Shamshirband, S.; Mosavi, A.; Kmet, T.; R. Várkonyi-Kóczy, A. Modeling Daily Pan Evaporation in Humid Cli-mates Using Gaussian Process Regression. Preprints 2019, 2019070351 (doi: 10.20944/preprints201907.0351.v1).

58. Shamshirband, S.; Hadipoor, M.; Baghban, A.; Mosavi, A.; Bukor J.; Annamaria R. Varkonyi-Koczy, Developing an ANFIS-PSO Model to predict mercury emissions in Combustion Flue Gases. Preprints 2019, 2019070165 (doi: 10.20944/preprints201907.0165.v1).

59. Shamshirband, S., et al., Ensemble models with uncertainty analysis for multi-day ahead forecasting of chlorophyll a concentration in coastal waters. Engineering Applications of Computational Fluid Mechanics, 2019. 13(1): p. 91-101.

60. Shamshirband, S., A. Mosavi, and T. Rabczuk, Particle swarm optimization model to predict scour depth around bridge pier. arXiv preprint arXiv:1906.08863, 2019.

61. Torabi, M., et al., A Hybrid Machine Learning Approach for Daily Prediction of Solar Radiation, in Lecture Notes in Networks and Systems. 2019, Springer. p. 266-274.

62. Ardabili, S., Mosavi, A., Mahmoudi, Mesri Gundoshmian, T, Nosratabadi, S., Var-konyi-Koczy, A., Modelling temperature 
variation of mushroom growing hall us-ing artificial neural networks, Preprints 2019.

63. Mesri Gundoshmian, T., Ardabili, S., Mosavi, A., Varkonyi-Koczy, A., Prediction of combine harvester performance using hybrid machine learning modeling and re-sponse surface methodology, Preprints 2019.

64. Ardabili, S., Mosavi, A., Varkonyi-Koczy, A., Systematic review of deep learning and machine learning models in biofuels research, Preprints 2019.

65. Ardabili, S., Mosavi, A., Varkonyi-Koczy, A., Advances in machine learning model-ing reviewing hybrid and ensemble methods, Preprints 2019.

66. Ardabili, S., Mosavi, A., Varkonyi-Koczy, A., Building Energy information: demand and consumption prediction with Machine Learning models for sustainable and smart cities, Preprints 2019.

67. Ardabili, S., Mosavi, A., Dehghani, M., Varkonyi-Koczy, A., Deep learning and machine learning in hydrological processes climate change and earth systems a systematic review, Preprints 2019.

68. Mohammadzadeh D., Karballaeezadeh, N., Mohemmi, M., Mosavi, A., Varkonyi-Koczy A., Urban Train Soil-Structure Interaction Modeling and Analysis, Preprints 2019.

69. Mosavi, A., Ardabili, S., Varkonyi-Koczy, A., List of deep learning models, Preprints 2019. 
70. Nosratabadi, S., Mosavi, A., Keivani, R., Ardabili, S., Aram, F., State of the art sur-vey of deep learning and machine learning models for smart cities and urban sustainability, Preprints 2019.

71. Perez, H.; H.M. Tah, J.; Mosavi, A.. Deep Learning for Detecting Building Defects Using Convolutional Neural Networks. Preprints 2019, 2019080068 (doi: 10.20944/preprints201908.0068.v1). 